\title{
Associations between maternal long-chain polyunsaturated fatty acid concentrations and child cognition at 7 years of age
}

Citation for published version (APA):

Brouwer-Brolsma, E., Van de Rest, O., Godschalk, R., Zeegers, M., Gielen, M., \& De Groot, R. (2017).

Associations between maternal long-chain polyunsaturated fatty acid concentrations and child cognition at 7 years of age: the MEFAB birth cohort. Prostaglandins, Leukotrienes, \& Essential Fatty Acids, 126, 92-97. https://doi.org/10.1016/j.plefa.2017.09.012

DOI:

10.1016/j.plefa.2017.09.012

Document status and date:

Published: 01/09/2017

Document Version:

Peer reviewed version

Please check the document version of this publication:

- A submitted manuscript is the version of the article upon submission and before peer-review. There can be important differences between the submitted version and the official published version of record. People interested in the research are advised to contact the author for the final version of the publication, or visit the DOI to the publisher's website.

- The final author version and the galley proof are versions of the publication after peer review.

- The final published version features the final layout of the paper including the volume, issue and page numbers.

Link to publication

\section{General rights}

Copyright and moral rights for the publications made accessible in the public portal are retained by the authors and/or other copyright owners and it is a condition of accessing publications that users recognise and abide by the legal requirements associated with these rights.

- Users may download and print one copy of any publication from the public portal for the purpose of private study or research.

- You may not further distribute the material or use it for any profit-making activity or commercial gain

- You may freely distribute the URL identifying the publication in the public portal.

If the publication is distributed under the terms of Article 25fa of the Dutch Copyright Act, indicated by the "Taverne" license above, please follow below link for the End User Agreement:

https://www.ou.nl/taverne-agreement

Take down policy

If you believe that this document breaches copyright please contact us at:

pure-support@ou.nl

providing details and we will investigate your claim.

Downloaded from https://research.ou.nl/ on date: 26 Apr. 2023 
Associations between maternal long-chain polyunsaturated fatty acid concentrations and child cognition at 7 years of age: the MEFAB birth cohort

EM Brouwer-Brolsma ${ }^{a}$, O van de Rest ${ }^{a}$, R Godschalk ${ }^{b}$, MPA Zeegers ${ }^{b}$, M Gielen ${ }^{b}$, RHM de Groot b,c

${ }^{a}$ Division of Human Nutrition, Wageningen University \& Research, Wageningen, The Netherlands

${ }^{\mathrm{b}}$ NUTRIM School for Nutrition and Translational Research in Metabolism, Department of Complex Genetics, Maastricht University, Maastricht, The Netherlands

c Faculty of Psychology and Educational Sciences, Welten Institute, Open University of the Netherlands, Heerlen, The Netherlands

${ }^{*}$ Corresponding author

PO Box 8129, 6700 EV Wageningen, The Netherlands

Tel: +31 (0)317 481287 Fax: +31(0)317 482782

E-mail: elske.brouwer-brolsma@wur.nl

Abbreviations: AA, arachidonic acid, 20:4n-6; DHA, docosahexaenoic acid, 22:5n-3; EPA, eicosapentaenoic acid, 20:5n-3; LCPUFAs, long-chain poly unsaturated fatty acids; K-ABC, KaufmanAssessment Battery; MEFAB, Maastricht Essential Fatty Acid Birth Cohort

Sources of support: The MEFAB study has been supported in part by grants from: Universiteitsfonds Limburg/SWOL; Nutricia Research Foundation (2015-24); The Dutch Organisation for Scientific Research (NWO, 90462 186); and The University Hospital of Maastricht (Profilerings Fonds). 


\section{Summary}

Dutch women of reproductive age have low concentrations of the fish fatty acids EPA and DHA. As the human brain incorporates high concentrations of these fatty acids in utero, these low EPA and DHA concentrations may adversely affect fetal brain health. We investigated associations between maternal $\mathrm{AA}, \mathrm{DHA}$, and EPA and cognitive function with the Kaufman Assessment Battery for Children, including sequential processing, simultaneous processing, and the mental processing composite, at 7 years of age $(n=292)$. Only $2 \%$ of the children performed more than one SD below the mental processing composite norm score. Fully-adjusted linear regression models did not show associations between maternal $\mathrm{AA}, \mathrm{DHA}$, or EPA status during any of the pregnancy trimesters and childhood sequential or simultaneous processing. Concluding, in this population, maternal fatty acid status during pregnancy was not associated with cognitive performance in Dutch children at age 7. 


\section{Abstract}

\section{Introduction}

Concentrations of the fish fatty acids EPA and DHA are low among Dutch women of reproductive age. As the human brain incorporates high concentrations of these fatty acids in utero, particularly during third trimester of gestation, these low EPA and DHA concentrations may have adverse consequences for fetal brain development and functioning.

\section{Methods}

Analyses were conducted using longitudinal observational data of 292 mother-child pairs participating in the MEFAB cohort. Maternal AA, DHA, and EPA were determined in plasma phospholipids obtained in three trimesters - by gas-liquid chromatography. Cognitive function was assessed at 7 years of age, using the Kaufman Assessment Battery for Children, resulting in three main outcome parameters: sequential processing (short-term memory), simultaneous processing (problem-solving skills), and the mental processing composite score. Spline regression and linear regression analyses were used to analyse the data, while adjusting for potential relevant covariates.

\section{Results}

Only $2 \%$ of the children performed more than one SD below the mental processing composite norm score. Children with lower test scores (<25\%) were more likely to have a younger mother with a higher pre-gestational BMI, less likely to be breastfed, and more likely to be born with a lower birth weight, compared to children with higher test scores ( $\geq 25 \%)$. Fully-adjusted linear regression models did not show associations of maternal AA, DHA, or EPA status during any of the pregnancy trimesters with childhood sequential and simultaneous processing.

\section{Conclusion}

Maternal fatty acid status during pregnancy was not associated with cognitive performance in Dutch children at age 7 .

Keywords: LCPUFA; cognitive performance; maternal; childhood; offspring. 


\section{Introduction}

Fish consumption in the Dutch population is low [1]. As fish is the predominant source of the longchain polyunsaturated fatty acids (LCPUFAs) eicosapentaenoic acid (EPA) and docosahexaenoic acid (DHA), the intake of these fatty acids is low as well. Specifically, Dutch women aged 19-30 have reported a median $\left(25^{\text {th }}-75^{\text {th }}\right.$ percentile) intake of 75 (41-133) mg EPA+DHA/day; those aged 31-51 years have reported an intake of 89 (49-155) mg EPA+DHA/day [1]. To put this into perspective, the European Food Safety Authority (EFSA) currently recommends pregnant women to consume 350-450 mg of EPA and DHA per day [2]. This low intake of these LCPUFAs, particularly DHA, in women of reproductive age is worrisome. Human studies namely indicate that the brain contains high concentrations of DHA [3], of which high quantities are already incorporated during the third trimester of gestation [4]. As the fetus principally depends on the DHA stores/intake of the mother, an adequate and balanced maternal DHA supply during gestation is assumed to be important for the developing fetal brain.

Besides DHA, another predominant LCPUFA in the human brain is arachidonic acid (AA). As AA can be obtained from a more abundant spectrum of food sources than EPA and DHA, including vegetable oils, poultry, eggs, nuts, and whole-grain products, the intake of $A A$ is assumed to be adequate in the Dutch population. Previous literature, however, does indicate an endogenous metabolic competition between n-3 fatty acids (e.g. EPA and DHA) and n-6 fatty acids (e.g. AA) [5]. Hence, not only the quantity of these LCPUFAs, but also their relative proportion may be of importance with respect to fetal brain development.

Studies investigating the impact of prenatal LCPUFA supplementation [6-12], intake [13, 14], or maternal or cord blood concentrations [11, 12, 15-20] on child brain development and function are inconclusive. Whereas a study among 11-year-old Inuit children showed significant associations between higher umbilical cord DHA concentration and a better performance on the digit span forward and California Verbal Learning Test-Children's Version [16], no associations were observed between umbilical cord DHA concentrations and cognitive performance in 7-year-old Norwegian [6] and Dutch children [19]. Beneficial associations were observed for maternal third trimester DHA concentrations and sequential processing scores at age 7 in Norwegian boys and girls [6] and language and verbal ability in 5-year-old children living at the Seychelles [15]. On the contrary, no associations were observed between second or second/third trimester maternal DHA concentrations and cognitive 
performance of the child at the age of 3 [13] and 18 months [18]. Clearly, most studies investigated maternal LCPUFA concentrations in late gestation or at delivery in relation to childhood cognition. However, as fetal brain development is a highly complex process that already starts in the first trimester, research on potential LCPUFA effects throughout the whole gestational period is warranted to provide more insight regarding specific LCPUFA requirements during the various critical periods of brain development.

The Maastricht Essential Fatty Acid Birth (MEFAB) cohort provides the unique opportunity to study associations between maternal essential fatty acid status throughout gestation (i.e. $<16,22,32$ gestational weeks) and childhood brain development and functioning. Previous analyses within the MEFAB cohort did not show associations between umbilical cord plasma AA and DHA and sequential and simultaneous processing at age 7 [19], but adverse associations were observed for maternal DHA status across trimesters and school performance based on arithmetic scores at age 7 [21]. Associations between fatty acid status across trimesters and cognitive performance at age 7 have not been explored yet. Therefore, the aim of this study was to examine the associations of maternal LCPUFA concentrations (i.e. AA, DHA, EPA, and DHA:AA) during gestation (i.e. <16, 22, 32 weeks) with childhood cognitive performance at 7 years of age as assessed with the Kaufman-Assessment Battery (K-ABC) in the MEFAB cohort. 


\section{Patients and Methods}

\subsection{Study population}

This study was performed using data of the MEFAB cohort, a prospective study designed to study relationships of essential fatty acid status during gestation and birth with metabolic health and cognitive, visual and motor function in Dutch children. Recruitment took place from 1989 to 1995. Pregnant women (<16 weeks) without any cardiovascular, neurological, renal or metabolic condition were eligible to participate. In total, $n=1,334$ women were screened; $n=131$ (10\%) were either excluded or dropped out before partus. At 7 years of age, $n=305$ participated in the cognitive testing procedures. Excluding those with missing data on maternal fatty acid status in all three trimesters resulted in a sample size of $n=292$ children for the analyses. More detailed information on the design and methods of the MEFAB cohort has been described elsewhere [22]. The Medical Ethics Committee of the University Hospital Maastricht/University Maastricht approved the study protocol and all families gave written informed consent.

\subsection{LCPUFA status}

Non-fasted blood samples were collected at study entry ( $<16$ gestational weeks), at 22 gestational weeks, 32 gestational weeks, and when the children were 7 years of age. Immediately after sampling, blood samples were stored at $-80^{\circ} \mathrm{C}$ until further analyses were conducted. In total, 41 different maternal fatty acids of plasma phospholipids (PL) were determined by gas-liquid chromatography [23], including C14:0, C15:0, C16:0, C17:0, C18:0, C20:0, C22:0, C23:0, C24:0, C16:1n-7, C18:1n-7, C20:1n-7, C18:1n-9, C18:2n-9, C20:1n9, C20:3n-9, C22:1n-9, C22:3n-9, C24:1n-9, C18:2n-6, C18:3n6, C20:2n-6, C20:3n-6, C20:4n-6, C22:2n-6, C22:4n-6, C22:5n-6, C24:2n-6, C18:3n-3, C20:3n-3, C20:4n-3, C20:5n-3, C22:3n-3, C22:5n-3, C22:6n-3, C16:0 DMA, C18:0 DMA, C18:1 DMA, C18:2n6tr, C16:1n-7tr, and C18:1n-9tr. For this study, maternal plasma phospholipid DHA (C22:6n-3), AA (C20:4n-6), and EPA (C20:5n-3) concentrations were selected, providing relative concentrations of DHA, AA, and EPA to total phospholipid-associated fatty acids (\% wt/wt).

\subsection{Cognitive performance}

Cognitive function was assessed with the Kaufman Assessment Battery for Children (K-ABC) [24], which evaluates two different types of information processing: sequential processing (i.e. short-term 
memory) and simultaneous processing (i.e. problem-solving skills). The sequential processing score is based on a variety of assignments in which the child arranges items in serial or sequential order, such as reproducing hand taps on a table, recalling numbers, and recalling objects as presented by the researcher. The simultaneous processing score is based on a variety of assignments in which the child completes a facial recognition task, identifies objects or scenes in an unfinished picture, replicates an object using rubber triangles, selects a picture to finalize another picture or complement another picture, has to remember and recall the location of specific pictures, and arranges a variety of pictures in a meaningful order. Together the sequential and simultaneous processing scores form the mental processing composite score, a measure of intelligence. For all three scores, a score of $100 \pm 15$ points is considered average (i.e. norm score); a score of 85 is one standard deviation below the norm score of 100 . Thus, higher scores indicate a better performance. The K-ABC was assessed according to a standard protocol, in a quiet room with blinded windows and by a single well-trained researcher.

\subsection{Covariates}

Information on child's sex (boy/girl, $n(\%)$ ), gestational age at birth (weeks), birth weight (grams), birth order (first/second/third/fourth/fifth, $n(\%)$ ), breastfeeding (no/yes, $n(\%)$ and duration), child's age at the time of the cognitive assessment (years), maternal age (years), maternal height $(\mathrm{m})$, maternal prepregnancy weight $(\mathrm{kg})$, maternal smoking during gestation (yes/no, $n(\%)$ ), and maternal alcohol consumption during gestation (yes/no, $n(\%)$ ) were collected by means of questionnaires. Bodyweight of the child was measured to the nearest $100 \mathrm{~g}$ using a digital scale (SECA) while wearing light underwear. Height of the child was measured to the nearest $\mathrm{mm}$ using a stadiometer (HoltainLTD, Crymych, UK). BMI was calculated as weight/height ${ }^{2}$. APGAR scores 5 minutes after birth were extracted from hospital records. Maternal pre-gestational BMI was calculated as weight/height ${ }^{2}$, using the measures of self-reported height and weight. Maternal intelligence was tested with Raven's Standard Progressive Matrices [25].

\subsection{Statistical analyses}

Participant characteristics are reported as mean with standard deviation (mean \pm SD), or $n$ with percentages $(n,(\%))$. Medians with interquartile range (median $(I Q R))$ were used to report skewed variables. Data is shown for the total population, by tertiles of maternal DHA status in the third 
trimester, and by cognitive performance score (normal vs. poor performance). Differences between tertiles of maternal DHA status and cognitive performance were analyzed by means of ANOVA in case of continuous variables and chi-square test in case of categorical variables. Correlations between the fatty acids across the trimesters were visualized by means of an ordination plot and quantified using Pearson's correlations. Linearity of the associations of maternal fatty acid status with childhood cognitive performance were investigated using restricted cubic spline regression as well as linear regression analyses by tertile of fatty acid status. As the aforementioned analyses did not point towards non-linearity, multivariable linear regression analyses was used to quantify the strength of the associations between maternal fatty acid status and cognitive performance of the child at age 7 . Model 1 was adjusted for child sex, birth weight, gestational age at birth, birth order, duration of breastfeeding, and child BMI at age 7 . Model 2 was adjusted for the covariates in model $1+$ maternal age, maternal intelligence, maternal pre-gestation BMI, maternal smoking, and maternal alcohol consumption during gestation. Model 3 was adjusted for the covariates in model $2+$ fatty acid status of the child at age 7 years. Given the intercorrelatedness between the fatty acids under study no adjustment for multiple testing was applied and hence a two-sided $P$-value of $\leq 0.05$ was considered statistically significant. Restricted cubic spline analyses were performed using R v2.15. The ordination plot was created using Canoco v5. All other statistical analyses were performed using the statistical package SAS, v9.3 (SAS Institute Inc., Cary, NC, USA). 


\section{Results}

Participant characteristics are shown in Table 1. In this population, the mean \pm SD maternal age was $29.9 \pm 4.2$ years and pre-gestational BMI $23.7 \pm 4.1 \mathrm{~kg} / \mathrm{m}^{2}$. Smoking was reported by $24 \%$ of the pregnant women; $3 \%$ reported to consume alcohol during pregnancy. Children were on average born with a gestational age of $40.1 \pm 3.3$ weeks, weighed $3,302 \pm 512$ grams, and were breastfed for a median $\left(25-75^{\text {th }}\right.$ percentile) period of $0(0-3)$ weeks. $56 \%$ of the children were boys. Most children were the first $(69 \%)$ or second $(24 \%)$ child of the family. None of the variables displayed in Table 1 differed over tertiles of maternal DHA status. Very few children performed more than one SD below the norm cognitive score, specifically $n=7(2 \%)$ for the mental processing composite score, $n=23(8 \%)$ for the sequential processing score, and $n=4(1 \%)$ for the simultaneous processing score. Nevertheless, children belonging to the group with the lowest cognitive test scores $(<25 \%)$ were more likely to have a younger mother $(28.3 \pm 4.4$ vs. $30.4 \pm 4.0$ years at the time of the pregnancy, $P<0.05)$, a mother with a higher pre-gestational BMI $\left(25.2 \pm 5.1\right.$ vs. $\left.23.3 \pm 3.7 \mathrm{~kg} / \mathrm{m}^{2}, \mathrm{P}<0.05\right)$, and were less likely to have received breastfeeding (35 vs. $50 \%, P<0.05$ ) compared to children with higher test scores $(\geq 25 \%)$. Children belonging to the group with the lowest cognitive test scores were also more likely to be born with a lower birth weight than children with higher test scores $(3,191 \pm 571 \mathrm{~g}$ vs. $3,338 \pm 487 \mathrm{~g}, \mathrm{P}<0.05)$. Absolute (wt/wt\%) concentrations of the fatty acids across trimesters are displayed in Figure 1. As shown by the clustering of the arrows in Figure 2, the fatty acids under study are generally strongly correlated across the trimesters.

Tests for non-linearity, visualization using restricted cubic splines, as well as linear regression analyses by tertiles (figures and data not shown) disclosed linear associations between the different fatty acids and childhood cognitive performance. Unadjusted linear regression models subsequently showed an inverse association between first trimester maternal AA concentrations and sequential processing scores $(\beta-0.99 \pm 0.51, P=0.05)$ (Table 2). Moreover, very modest non-significant inverse trends between first and second trimester maternal AA concentrations and simultaneous processing scores were observed $(\beta-0.83 \pm 0.48, P=0.09$ and $-0.98 \pm 0.56, P=0.08)$. As the sequential and simultaneous processing scores form the mental processing composite score, these trends were also reflected in the results for this overall mental composite score. 
The modest associations of first and second trimester $A A$ concentrations with sequential $(\beta-0.68 \pm 0.57$,

221

222

223

224

225 $P=0.23$ and $-0.55 \pm 0.65, P=0.70)$ and simultaneous processing $(\beta-0.40 \pm 0.52, P=0.44$ and $-0.19 \pm 0.61$, $\mathrm{P}=0.75)$ fully disappeared after further adjustment for child and maternal characteristics. Neither crude nor adjusted models pointed towards associations between maternal DHA concentrations and childhood cognitive performance. Crude models did show a borderline non-significant positive association between third trimester maternal EPA concentrations and sequential processing scores ( $\beta$ 7.16 $\pm 3.83, P=0.06)$. After adjustment for child as well as maternal characteristics a trend towards an association remained $(\beta 7.28 \pm 4.05, P=0.07)$, which somewhat further attenuated after adjustment for EPA status of the child at 7 years of age $(\beta 7.28 \pm 4.26, P=0.09)$. No associations were observed between maternal DHA:AA ratio and cognitive performance of the child at age 7 years. 


\section{Discussion and Conclusions}

This study did not show significant associations of maternal fatty acid status during the different trimesters of gestation with sequential (short-term memory) or simultaneous (problem-solving skills) processing of the children at age 7.

A priori, associations with childhood cognitive performance were particularly hypothesized for third trimester maternal $\mathrm{AA}$ and DHA concentrations. Specifically, AA and DHA are considered to be the most important fatty acids for normal brain growth and development, amongst others due to their role in neuronal growth, differentiation, and signaling [26]. These potential effects are particularly expected during the third trimester as this is the period with the highest transfer of fatty acids from the mother to the unborn child [27]. In contrast to these expectations, we did not observe any association between maternal AA, DHA, and EPA status across trimesters and childhood cognitive performance. Our findings are in line with previous analyses within this cohort examining associations of umbilical cord AA and DHA concentrations with cognitive performance at age 7 , which also not provided evidence for significant associations between the variables under study [19].

In this study no associations were observed between first trimester fatty acid status and offspring cognition. To the best of our knowledge, this is the first study examining associations between first trimester fatty acid concentrations and childhood cognitive performance and hence this association warrants further verification in other cohorts. We did also not observe associations between second trimester fatty acid status and childhood cognitive performance. These findings are in line with the findings in the Project Viva cohort showing no associations between second trimester maternal erythrocyte DHA concentrations with cognitive performance at 3-years-old [13] and data of an Italian cohort investigating the link between second/third trimester LCPUFAs and child neurodevelopment [18]. Our null-findings with respect to third trimester DHA and AA concentrations and cognitive performance of the child are in contrast to findings of several other studies. After full-adjustment, Strain and colleagues observed associations between higher third trimester maternal DHA concentrations and higher scores on the Preschool Language Scale-Revised for language ( $\beta$ 41.3, SE 19.3, $P=0.03$ ) as well as verbal ability ( $\beta$ 24.6, SE 12.2, $P=0.04$ ), but not with Kaufman Brief Intelligence Test scores ( $n=225$, aged $\pm 5 y$, the Seychelles) [15]. In addition, this study showed 
associations of third trimester maternal $A A$ concentrations with language $(\beta-15.8, S E 6.5, P=0.02)$, auditory comprehension ( $\beta-7.5$, SE 3.2, $P=0.02)$, and verbal ability $(\beta-8.3, S E 4.1, P=0.04)$ [15]. In 7 year old Norwegian children $(n=143)$, third trimester maternal DHA concentrations were positively associated with sequential processing scores of the $K-A B C(\beta 0.06 \pm 0.03, P<0.05)[6]$. Our null-findings with respect to maternal EPA concentrations and childhood cognitive performance in our study are in line with the null-findings in the Norwegian study [6], Project Viva [13], the Seychelles study [15], as well as the Italian study [18].

Unfortunately, none of the above-summarized studies analyzed data on fatty acid status throughout gestation. Previous analyses within the MEFAB cohort did investigate associations between fatty acid status across trimesters and school performance at age 7 [21]. These analyses pointed towards significant adverse associations between maternal DHA status in all three trimesters and arithmetic scores. Adverse associations were also shown of maternal EPA concentrations in the first and second trimester with arithmetic scores, first trimester EPA with spelling, and first trimester AA with arithmetic and reading scores [21]. However, although cognition and school performance are related, these terms cannot be exchanged, as school performance is probably also affected by other factors such as perseverance and study time. Possible explanations for the inconsistent findings for the studies on maternal fatty acid status and childhood cognition are that they may relate to methodological differences in cognitive assessment (e.g. method lacking sensitivity), power-issues, and limited variation in fatty acid status. It has also been postulated that early life effects of LCPUFA may be transient and that effects are overruled by effects of the LCPUFA supply in postnatal life [18]. However, this last idea is contradicted by the various studies showing significant associations between maternal fatty acid status during gestation and cognitive performance at 5, 7, and 11-years old [6, 15, 16]. Moreover, our models did not substantially change after adjustment for fatty acid status of the child at the age of 7 years.

Finally, in order to put our findings further into perspective, there are several study specific characteristics that warrant some discussion. First of all, cognitive performance was assessed with the $\mathrm{K}-\mathrm{ABC}$. Our test results indicate that only very few children in this population performed more than one SD below the norm-score, which may indicate that this test was not sensitive enough to detect robust 
associations. However, our test scores and the variation in these scores were relatively similar to the test scores in the study by Helland and colleagues [6], who used the same cognitive test battery and did observe an association between maternal third trimester DHA and sequential processing of the child. Secondly, maternal fatty acids were determined using non-fasted blood samples, which may raise doubts about the long-term representativeness of the measured concentrations. However, as previous work has shown that the incorporation of EPA and DHA in erythrocyte membranes has a half-life of approximately 28 days, where concentrations start to rise after 3 days of fish oil supplementation [28], we do not expect a substantial influence of very recent EPA and DHA intakes on the EPA/DHA concentrations measured. Another limitation of our study may be that only 305 children of the original 1203 mother-offspring pairs completed the cognitive tests at age 7 . Though, Bakker and colleagues (2003) compared the data of participating and non-participating children with respect to their clinical baseline characteristics and did not show significant differences between these two groups [19]. Despite aforementioned limitations, a unique feature of this study is that women were included in a very early stage of gestation, providing us with valuable data on fatty acids status from the first to the third trimester. Furthermore, as fatty acids were measured in plasma phospholipids, a generally accepted technique to determine long-term dietary fatty acids intake, it can be confidently stated that the exposure marker studied provided a reliable reflection of long-term fatty acid status. Last but not least, children were followed for on average 7 years of age, which offered the possibility to study potential long-term effects of early-life LCPUFA exposure.

All in all, we conclude that our analyses in the Dutch MEFAB cohort do not provide evidence for a negative nor a positive association between maternal LCPUFA concentrations throughout gestation and cognitive performance at 7-years-old.

\section{Acknowledgments}

The authors thank all participants, principal investigators and collaborators of the MEFAB birth cohort.

Funding: The MEFAB study has been supported in part by grants from: Universiteitsfonds Limburg/SWOL; Nutricia Research Foundation (2015-24); The Dutch Organisation for Scientific Research (NWO, 90462 186); and The University Hospital of Maastricht (Profilerings Fonds). 

data acquisition and data management. All authors contributed to the interpretation of data, revision of 322 the manuscript, and all authors approved the version to be submitted. Declaration of interest: EMBB, OvdR, RG, MPAZ, MG, and RHMdG have nothing to disclose. 
[1] C.T.M. van Rossum, H.P. Fransen, J. Verkaik-Kloosterman, E.J.M. Buurma-Rethans, M.C. Ocke, Dutch National Food Consumption Survey 2007-2010 : Diet of children and adults aged 7 to 69 years., in, National Institute for Public Health and the Environment (RIVM) 2011.

[2] EFSA Panel on Dietetic Products, and Allergies (NDA), Scientific Opinion on Dietary Reference Values for fats, including saturated fatty acids, polyunsaturated fatty acids, monounsaturated fatty acids, trans fatty acids, and cholesterol., EFSA Journal, 8 (2010) 1-107.

[3] J.S. O'Brien, D.L. Fillerup, J.F. Mead, Quantification and fatty acid and fatty aldehyde composition of ethanolamine, choline, and serine glycerophosphatides in human cerebral grey and white matter, Journal of lipid research, 5 (1964) 329-338.

[4] M.T. Clandinin, J.E. Chappell, S. Leong, T. Heim, P.R. Swyer, G.W. Chance, Intrauterine fatty acid accretion rates in human brain: implications for fatty acid requirements, Early human development, 4 (1980) 121-129.

[5] G. Schmitz, J. Ecker, The opposing effects of $n-3$ and n-6 fatty acids, Progress in lipid research, 47 (2008) 147-155.

[6] I.B. Helland, L. Smith, B. Blomen, K. Saarem, O.D. Saugstad, C.A. Drevon, Effect of supplementing pregnant and lactating mothers with n-3 very-long-chain fatty acids on children's IQ and body mass index at 7 years of age, Pediatrics, 122 (2008) e472-479.

[7] I.B. Helland, L. Smith, K. Saarem, O.D. Saugstad, C.A. Drevon, Maternal supplementation with very-longchain $n-3$ fatty acids during pregnancy and lactation augments children's IQ at 4 years of age, Pediatrics, 111 (2003) e39-44.

[8] J.A. Dunstan, K. Simmer, G. Dixon, S.L. Prescott, Cognitive assessment of children at age 2(1/2) years after maternal fish oil supplementation in pregnancy: a randomised controlled trial, Archives of disease in childhood. Fetal and neonatal edition, 93 (2008) F45-50.

[9] C.L. Jensen, R.G. Voigt, T.C. Prager, Y.L. Zou, J.K. Fraley, J.C. Rozelle, M.R. Turcich, A.M. Llorente, R.E. Anderson, W.C. Heird, Effects of maternal docosahexaenoic acid intake on visual function and neurodevelopment in breastfed term infants, The American journal of clinical nutrition, 82 (2005) 125-132.

[10] C. Campoy, M.V. Escolano-Margarit, R. Ramos, M. Parrilla-Roure, G. Csabi, J. Beyer, M.C. RamirezTortosa, A.M. Molloy, T. Decsi, B.V. Koletzko, Effects of prenatal fish-oil and 5-methyltetrahydrofolate supplementation on cognitive development of children at 6.5 y of age, The American journal of clinical nutrition, 94 (2011) 1880S-1888S.

[11] S.A. van Goor, D.A. Dijck-Brouwer, J.J. Erwich, A. Schaafsma, M. Hadders-Algra, The influence of supplemental docosahexaenoic and arachidonic acids during pregnancy and lactation on neurodevelopment at eighteen months, Prostaglandins, leukotrienes, and essential fatty acids, 84 (2011) 139-146.

[12] M.V. Escolano-Margarit, R. Ramos, J. Beyer, G. Csabi, M. Parrilla-Roure, F. Cruz, M. Perez-Garcia, M. Hadders-Algra, A. Gil, T. Decsi, B.V. Koletzko, C. Campoy, Prenatal DHA status and neurological outcome in children at age 5.5 years are positively associated, The Journal of nutrition, 141 (2011) 1216-1223.

[13] E. Oken, J.S. Radesky, R.O. Wright, D.C. Bellinger, C.J. Amarasiriwardena, K.P. Kleinman, H. Hu, M.W. Gillman, Maternal fish intake during pregnancy, blood mercury levels, and child cognition at age 3 years in a US cohort, American journal of epidemiology, 167 (2008) 1171-1181.

[14] J.Y. Bernard, M. Armand, A. Forhan, M. de Agostini, M.A. Charles, B. Heude, Early life exposure to polyunsaturated fatty acids and psychomotor development in children from the EDEN mother-child cohort, Oilseeds \& fats Crops and Lipids, 23 (2016) 1-9.

[15] J.J. Strain, P.W. Davidson, S.W. Thurston, D. Harrington, M.S. Mulhern, A.J. McAfee, E. van Wijngaarden, C.F. Shamlaye, J. Henderson, G.E. Watson, G. Zareba, D.A. Cory-Slechta, M. Lynch, J.M. Wallace, E.M. McSorley, M.P. Bonham, A. Stokes-Riner, J. Sloane-Reeves, J. Janciuras, R. Wong, T.W. Clarkson, G.J. Myers, Maternal PUFA status but not prenatal methylmercury exposure is associated with children's language functions at age five years in the Seychelles, The Journal of nutrition, 142 (2012) 1943-1949.

[16] O. Boucher, M.J. Burden, G. Muckle, D. Saint-Amour, P. Ayotte, E. Dewailly, C.A. Nelson, S.W. Jacobson, J.L. Jacobson, Neurophysiologic and neurobehavioral evidence of beneficial effects of prenatal omega-3 fatty acid intake on memory function at school age, The American journal of clinical nutrition, 93 (2011) 1025-1037. [17] A. Ghys, E. Bakker, G. Hornstra, M. van den Hout, Red blood cell and plasma phospholipid arachidonic and docosahexaenoic acid levels at birth and cognitive development at 4 years of age, Early human development, 69 (2002) 83-90.

[18] F. Valent, M. Mariuz, M. Bin, D. Little, D. Mazej, V. Tognin, J. Tratnik, A.J. McAfee, M.S. Mulhern, M. Parpinel, M. Carrozzi, M. Horvat, G. Tamburlini, F. Barbone, Associations of prenatal mercury exposure from maternal fish consumption and polyunsaturated fatty acids with child neurodevelopment: a prospective cohort study in Italy, Journal of epidemiology / Japan Epidemiological Association, 23 (2013) 360-370.

[19] E.C. Bakker, A.J. Ghys, A.D. Kester, J.S. Vles, J.S. Dubas, C.E. Blanco, G. Hornstra, Long-chain polyunsaturated fatty acids at birth and cognitive function at $7 \mathrm{y}$ of age, European journal of clinical nutrition, 57 (2003) 89-95.

[20] H. Bouwstra, J. Dijck-Brouwer, T. Decsi, G. Boehm, E.R. Boersma, F.A. Muskiet, M. Hadders-Algra, Neurologic condition of healthy term infants at 18 months: positive association with venous umbilical DHA status and negative association with umbilical trans-fatty acids, Pediatric research, 60 (2006) 334-339.

[21] I.S. van der Wurff, E.C. Bakker, G. Hornstra, P.A. Kirschner, M. Gielen, R.W. Godschalk, S. Kremers, M.P. Zeegers, R.H. de Groot, Association between prenatal and current exposure to selected LCPUFAs and school performance at age 7, Prostaglandins, leukotrienes, and essential fatty acids, 108 (2016) 22-29.

[22] I.S.M. van der Wurff, R.H.M. de Groot, N. Stratakis, M. Gielen, G. Hornstra, M. Zeegers, Maastricht essential fatty acid birth cohort, Lipid Technology, 27 (2015) 59-62. 
[23] M.D. Al, A.C. van Houwelingen, A.D. Kester, T.H. Hasaart, A.E. de Jong, G. Hornstra, Maternal essential fatty acid patterns during normal pregnancy and their relationship to the neonatal essential fatty acid status, The British journal of nutrition, 74 (1995) 55-68.

[24] A.S. Kaufman, N.L. Kaufman, Kaufman Assessment Battery for Children, in, American Guidance Service, Circle Pines, MN, 1983.

[25] J. Raven, J. Court, J. Raven, Standard Progressive Matrices., Oxford Psychologists Press, Oxford 1996.

[26] J.R. Marszalek, H.F. Lodish, Docosahexaenoic acid, fatty acid-interacting proteins, and neuronal function: breastmilk and fish are good for you, Annual review of cell and developmental biology, 21 (2005) 633-657.

[27] C. Montgomery, B.K. Speake, A. Cameron, N. Sattar, L.T. Weaver, Maternal docosahexaenoic acid supplementation and fetal accretion, The British journal of nutrition, 90 (2003) 135-145.

[28] M.B. Katan, J.P. Deslypere, A.P. van Birgelen, M. Penders, M. Zegwaard, Kinetics of the incorporation of dietary fatty acids into serum cholesteryl esters, erythrocyte membranes, and adipose tissue: an 18-month controlled study, Journal of lipid research, 38 (1997) 2012-2022. 
Figure 1. Fatty acid status (\% wt/wt) across trimesters. AA: $9.61 \pm 1.47$ (T1), $8.58 \pm 1.29$ (T2), $8.15 \pm 1.17$ (T3); DHA: $4.02 \pm 0.83$ (T1), $4.16 \pm 0.84$ (T2), $4.00 \pm 0.74$ (T3); EPA: $0.52 \pm 0.37$ (T1), $0.41 \pm 0.36$ (T2), $0.35 \pm 0.20$ (T3); DHA:AA: $0.42 \pm 0.09$ (T1), $0.49 \pm 0.12(\mathrm{~T} 2), 0.50 \pm 0.11(\mathrm{~T} 3)$.

Figure 2. Ordination plot. Arrows indicate the strength of the correlations between the different fatty acids (\% wt/wt) as measured throughout the three trimesters (T1, T2, and T3). In general, arrows for a specific fatty acid are clustered in the same region, indicating strong correlations between the fatty acids across trimester. Specifically, Pearson correlations for AA-T1 vs T2 and T3 were $0.74(P<0.0001)$ and $0.69(P<0.0001)$. Pearson correlations for DHA-T1 vs T2 and T3 were $0.58(P<0.0001)$ and $0.51(P<0.0001)$. Pearson correlations for EPA-T1 vs T2 and T3 were $0.24(P=0.0001)$ and $0.19(P=0.002)$. 
Table 1. Population characteristics by tertiles of third trimester DHA status

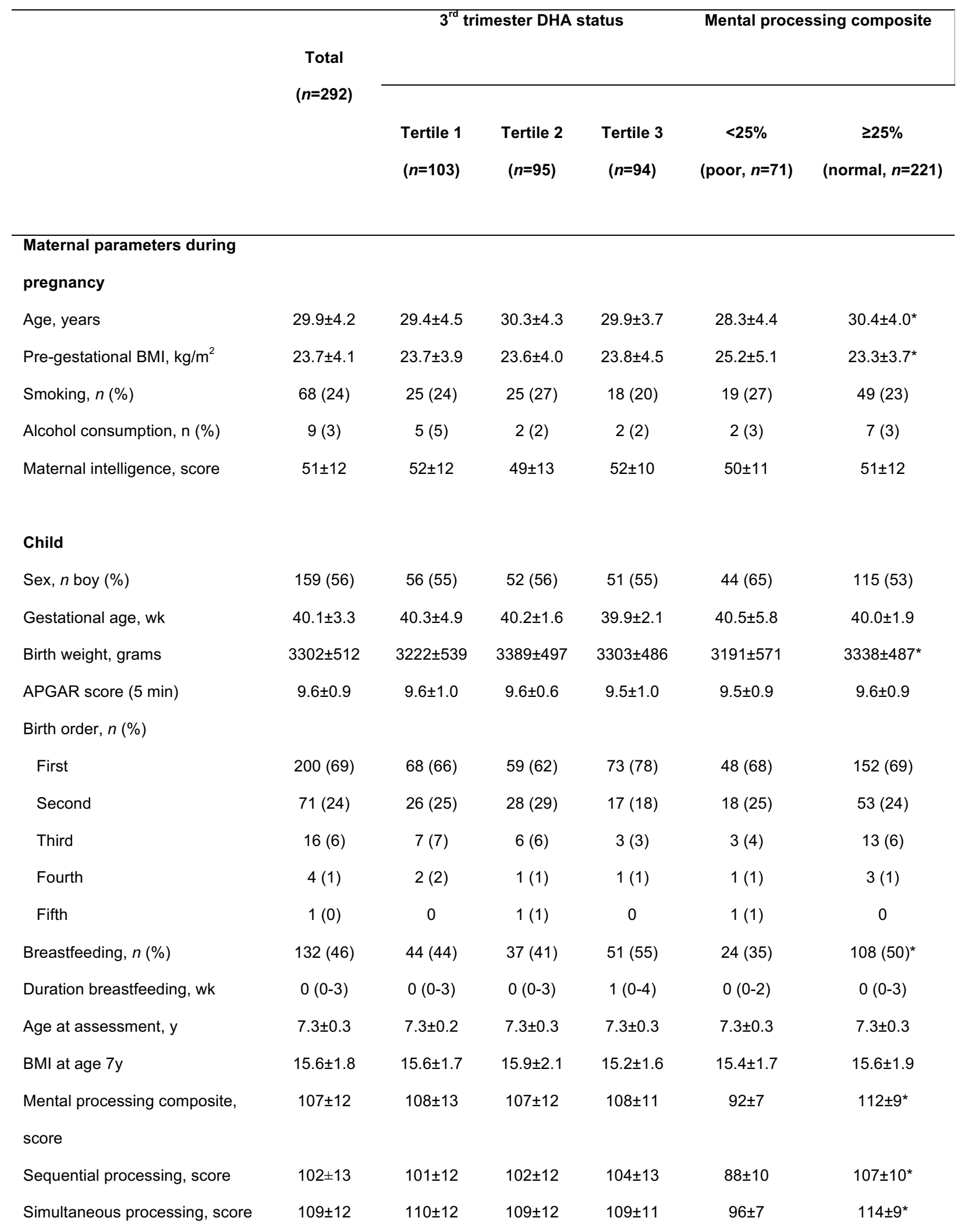

Values are expressed as mean $\pm S D$, median (IQR), or $n(\%)$. To compare baseline characteristics over tertiles of third trimester DHA status or cognitive performance, chi-squared tests were performed for categorical variables and 1-way analysis of variance for continuous variables. * indicates $\mathrm{P}<0.05$. Missing: Sex child $n=6$, Smoking $n=4$, Alcohol $n=5$, pre-pregnancy BMI $n=31$, gestational age $n=14$, birthweight $n=1$, breastfeeding $n=8$, age at assessment $n=6$, BMl at age $7 n=11$, APGAR score after 5 minutes $n=3$. 
Table 2. Associations of $1^{\text {st }}, 2^{\text {nd }}$, and $3^{\text {rd }} A A, D H A, E P A$, and DHA:AA status with cognitive performance at age 7 years.

\begin{tabular}{|c|c|c|c|c|c|c|c|c|c|}
\hline & & \multicolumn{2}{|c|}{$\begin{array}{l}\text { Crude model } \\
\text { (T1 } n=281 ; \mathrm{T} 2 n=261 ; \mathrm{T} 3 \\
n=275)\end{array}$} & \multicolumn{2}{|c|}{$\begin{array}{c}\text { Model } 1 \\
\text { (T1 } n=254 ; \text { T2 } n=238 \text {, T3 } \\
n=252)\end{array}$} & \multicolumn{2}{|c|}{$\begin{array}{c}\text { Model } 2 \\
\begin{array}{l}n=229 ; \\
n=225)\end{array}\end{array}$} & \multicolumn{2}{|c|}{$\begin{array}{c}\text { Model } 3 \\
\begin{array}{c}n=199 ; \text { T2 } n=183 ; \text { T3 } \\
n=193)\end{array}\end{array}$} \\
\hline & & $\beta \pm S D$ & $P$ & $\beta \pm S D$ & $P$ & $\beta \pm S D$ & $P$ & $\beta \pm S D$ & $P$ \\
\hline $\begin{array}{l}\text { Sequential } \\
\text { score }\end{array}$ & ocessing & & & & & & & & \\
\hline Fatty acid & Trimester & & & & & & & & \\
\hline AA & 1 & $-0.99 \pm 0.51$ & 0.05 & $-1.21 \pm 0.55$ & 0.03 & $-0.68 \pm 0.57$ & 0.23 & $-0.73 \pm 0.62$ & 0.24 \\
\hline AA & 2 & $-1.04 \pm 0.61$ & 0.09 & $-0.96 \pm 0.64$ & 0.14 & $-0.25 \pm 0.65$ & 0.70 & $-0.12 \pm 0.70$ & 0.87 \\
\hline AA & 3 & $-0.52 \pm 0.66$ & 0.43 & $-0.30 \pm 0.69$ & 0.66 & $0.02 \pm 0.72$ & 0.97 & $-0.10 \pm 0.79$ & 0.90 \\
\hline DHA & 1 & $0.55 \pm 0.91$ & 0.55 & $-0.15 \pm 0.96$ & 0.88 & $1.21 \pm 1.00$ & 0.23 & $1.58 \pm 1.05$ & 0.14 \\
\hline DHA & 2 & $0.01 \pm 0.95$ & 0.99 & $-0.16 \pm 0.98$ & 0.87 & $0.40 \pm 0.97$ & 0.68 & $0.56 \pm 1.04$ & 0.59 \\
\hline $\mathrm{DHA}$ & 3 & $0.96 \pm 1.04$ & 0.36 & $0.29 \pm 1.10$ & 0.79 & $1.06 \pm 1.15$ & 0.35 & $1.06 \pm 1.23$ & 0.39 \\
\hline EPA & 1 & $-1.39 \pm 2.04$ & 0.50 & $-2.28 \pm 2.14$ & 0.29 & $-0.56 \pm 2.21$ & 0.80 & $0.07 \pm 3.22$ & 0.98 \\
\hline EPA & 2 & $-1.27 \pm 2.22$ & 0.57 & $-2.62 \pm 2.26$ & 0.25 & $-2.23 \pm 2.13$ & 0.30 & $-2.53 \pm 2.18$ & 0.25 \\
\hline EPA & 3 & $7.16 \pm 3.83$ & 0.06 & $6.05 \pm 4.05$ & 0.14 & $7.28 \pm 4.05$ & 0.07 & $7.28 \pm 4.26$ & 0.09 \\
\hline DHA:AA & 1 & $14.14 \pm 7.96$ & 0.08 & $9.73 \pm 8.34$ & 0.24 & $12.96 \pm 8.16$ & 0.11 & $16.34 \pm 8.95$ & 0.07 \\
\hline DHA:AA & 2 & $4.24 \pm 6.84$ & 0.54 & $2.00 \pm 7.03$ & 0.78 & $1.10 \pm 6.77$ & 0.87 & $-0.15 \pm 7.08$ & 0.98 \\
\hline DHA:AA & 3 & $5.73 \pm 7.21$ & 0.43 & $0.16 \pm 7.53$ & 0.98 & $3.36 \pm 7.85$ & 0.67 & $3.60 \pm 8.47$ & 0.67 \\
\hline \multicolumn{9}{|c|}{ processing score } & \\
\hline Fatty acid & Trimester & & & & & & & & \\
\hline AA & 1 & $-0.83 \pm 0.48$ & 0.09 & $-0.67 \pm 0.50$ & 0.18 & $-0.40 \pm 0.52$ & 0.44 & $-0.30 \pm 0.58$ & 0.61 \\
\hline AA & 2 & $-0.98 \pm 0.56$ & 0.08 & $-0.63 \pm 0.58$ & 0.28 & $-0.19 \pm 0.61$ & 0.75 & $-0.16 \pm 0.68$ & 0.81 \\
\hline AA & 3 & $-0.61 \pm 0.59$ & 0.30 & $-0.04 \pm 0.61$ & 0.95 & $0.13 \pm 0.65$ & 0.84 & $0.05 \pm 0.72$ & 0.95 \\
\hline DHA & 1 & $-0.33 \pm 0.85$ & 0.70 & $-0.55 \pm 0.88$ & 0.53 & $-0.14 \pm 0.91$ & 0.88 & $0.01 \pm 0.98$ & 0.99 \\
\hline DHA & 2 & $-0.19 \pm 0.87$ & 0.82 & $-0.05 \pm 0.89$ & 0.95 & $-0.14 \pm 0.91$ & 0.88 & $-0.22 \pm 0.99$ & 0.82 \\
\hline DHA & 3 & $-0.84 \pm 0.94$ & 0.37 & $-1.09 \pm 0.98$ & 0.27 & $-1.54 \pm 1.02$ & 0.13 & $-1.81 \pm 1.11$ & 0.10 \\
\hline EPA & 1 & $-0.83 \pm 1.91$ & 0.66 & $-1.39 \pm 1.95$ & 0.48 & $-1.17 \pm 2.02$ & 0.56 & $-1.09 \pm 2.96$ & 0.71 \\
\hline EPA & 2 & $-0.67 \pm 2.03$ & 0.74 & $-1.44 \pm 2.05$ & 0.48 & $-0.56 \pm 2.00$ & 0.78 & $-1.32 \pm 2.07$ & 0.53 \\
\hline EPA & 3 & $3.61 \pm 3.47$ & 0.30 & $2.69 \pm 3.63$ & 0.46 & $2.82 \pm 3.66$ & 0.44 & $2.51 \pm 3.87$ & 0.52 \\
\hline DHA:AA & 1 & $7.20 \pm 7.49$ & 0.34 & $3.70 \pm 7.60$ & 0.63 & $2.69 \pm 7.50$ & 0.72 & $3.10 \pm 8.31$ & 0.71 \\
\hline DHA:AA & 2 & $5.44 \pm 6.27$ & 0.39 & $3.40 \pm 6.36$ & 0.59 & $0.13 \pm 6.33$ & 0.98 & $-0.90 \pm 6.73$ & 0.89 \\
\hline DHA:AA & 3 & $-1.75 \pm 6.50$ & 0.79 & $-7.96 \pm 6.71$ & 0.24 & $-11.47 \pm 7.00$ & 0.10 & $-12.53 \pm 7.60$ & 0.10 \\
\hline
\end{tabular}

Mental processing 
score

Fatty acid Trimester

\begin{tabular}{|c|c|c|c|c|c|c|c|c|c|}
\hline AA & 1 & $-1.03 \pm 0.49$ & 0.04 & $-1.02 \pm 0.52$ & 0.05 & $-0.59 \pm 0.54$ & 0.27 & $-0.52 \pm 0.59$ & 0.38 \\
\hline AA & 2 & $-1.17 \pm 0.58$ & 0.05 & $-0.90 \pm 0.61$ & 0.14 & $-0.19 \pm 0.61$ & 0.75 & $-0.19 \pm 0.69$ & 0.79 \\
\hline AA & 3 & $-0.64 \pm 0.61$ & 0.29 & $-0.15 \pm 0.64$ & 0.81 & $0.09 \pm 0.66$ & 0.89 & $0.00 \pm 0.74$ & 0.99 \\
\hline DHA & 1 & $-0.01 \pm 0.87$ & 0.99 & $-0.47 \pm 0.91$ & 0.61 & $0.42 \pm 0.93$ & 0.65 & $0.71 \pm 2.00$ & 0.48 \\
\hline $\mathrm{DHA}$ & 2 & $-0.15 \pm 0.90$ & 0.86 & $-0.14 \pm 0.93$ & 0.88 & $0.09 \pm 0.93$ & 0.92 & $0.13 \pm 1.01$ & 0.90 \\
\hline $\mathrm{DHA}$ & 3 & $-0.18 \pm 0.97$ & 0.86 & $-0.64 \pm 1.02$ & 0.53 & $-0.61 \pm 1.05$ & 0.56 & $-0.78 \pm 1.15$ & 0.50 \\
\hline EPA & 1 & $-1.30 \pm 1.96$ & 0.51 & $-2.06 \pm 2.02$ & 0.31 & $-1.16 \pm 2.07$ & 0.58 & $-0.96 \pm 3.04$ & 0.75 \\
\hline EPA & 2 & $-0.97 \pm 2.11$ & 0.65 & $-2.07 \pm 2.14$ & 0.33 & $-1.30 \pm 2.04$ & 0.53 & $-1.96 \pm 2.12$ & 0.36 \\
\hline EPA & 3 & $5.73 \pm 3.58$ & 0.11 & $4.63 \pm 3.77$ & 0.22 & $5.21 \pm 3.74$ & 0.17 & $4.90 \pm 3.97$ & 0.22 \\
\hline DHA:AA & 1 & $11.22 \pm 7.64$ & 0.14 & $6.95 \pm 7.89$ & 0.38 & $7.64 \pm 7.66$ & 0.32 & $9.32 \pm 8.51$ & 0.28 \\
\hline DHA:AA & 2 & $5.59 \pm 6.53$ & 0.39 & $3.22 \pm 6.66$ & 0.63 & $0.73 \pm 6.48$ & 0.91 & $-0.49 \pm 6.88$ & 0.94 \\
\hline DHA:AA & 3 & $0.99 \pm 6.74$ & 0.88 & $-5.72 \pm 7.00$ & 0.41 & $-6.59 \pm 7.21$ & 0.36 & $-7.24 \pm 7.87$ & 0.36 \\
\hline
\end{tabular}

Associations are adjusted for child sex, birth weight, gestational age at birth, birth order, breastfeeding (yes/no), child BMl at age 7 (model 1) + maternal age, maternal intelligence, maternal pre-pregnancy BMI, maternal smoking (yes/no) + maternal alcohol consumption during pregnancy (yes/no) (model 2) + fatty acid status at age 7 (model 3). 